\title{
Identification of animal movement patterns using tri-axial accelerometry
}

\author{
Emily L. C. Shepard ${ }^{1, *}$, Rory P. Wilson ${ }^{1}$, Flavio Quintana ${ }^{2,3}$, Agustina Gómez Laich ${ }^{3}$, \\ Nikolai Liebsch ${ }^{1}$, Diego A. Albareda ${ }^{4}$, Lewis G. Halsey ${ }^{5}$, Adrian Gleiss ${ }^{1}$, \\ David T. Morgan ${ }^{1}$, Andrew E. Myers ${ }^{6}$, Chris Newman ${ }^{7}$, David W. Macdonald ${ }^{7}$ \\ ${ }^{1}$ Biological Sciences, Institute of Environmental Sustainability, Swansea University, Swansea SA2 8PP, UK \\ ${ }^{2}$ Centro Nacional Patagónico (CENPAT)-CONICET, (9120) Puerto Madryn, Chubut, Argentina \\ ${ }^{3}$ Wildlife Conservation Society, 2300 Southern Boulevard, New York, New York 10460, USA \\ ${ }^{4}$ Buenos Aires Zoo, Av. Sarmiento and Av. The Heras, Buenos Aires, Argentina \\ ${ }^{5}$ School of Human and Life Sciences, Roehampton University, London SW15 4JD, UK \\ ${ }^{6}$ Large Pelagics Research Laboratory, University of New Hampshire, Durham, New Hampshire 03824, USA \\ ${ }^{7}$ Wildlife Conservation Research Unit, University of Oxford, Tubney House, Abingdon OX13 5QL, UK
}

\begin{abstract}
An animal's behaviour is a response to its environment and physiological condition, and as such, gives vital clues as to its well-being, which is highly relevant in conservation issues. Behaviour can generally be typified by body motion and body posture, parameters that are both measurable using animal-attached accelerometers. Interpretation of acceleration data, however, can be complex, as the static (indicative of posture) and dynamic (motion) components are derived from the total acceleration values, which should ideally be recorded in all 3-dimensional axes. The principles of triaxial accelerometry are summarised and discussed in terms of the commonalities that arise in patterns of acceleration across species that vary in body pattern, life-history strategy, and the medium they inhabit. Using tri-axial acceleration data from deployments on captive and free-living animals ( $\mathrm{n}=12$ species), behaviours were identified that varied in complexity, from the rhythmic patterns of locomotion, to feeding, and more variable patterns including those relating to social interactions. These data can be combined with positional information to qualify patterns of area-use and map the distribution of target behaviours. The range and distribution of behaviour may also provide insight into the transmission of disease. In this way, the measurement of tri-axial acceleration can provide insight into individual and population level processes, which may ultimately influence the effectiveness of conservation practice.
\end{abstract}

KEY WORDS: Acceleration - Archival tag - Satellite tracking - Biotelemetry - Time budget • Energy expenditure $\cdot$ Stroke frequency

Resale or republication not permitted without written consent of the publisher

\section{INTRODUCTION}

An animal's behaviour is a fundamental part of its biology, being a manifestation of its response to the environment (which, if appropriate, will increase its fitness) as well as being connected to its physiological condition. This explains why the study of animal behaviour is so widespread and complex. Although measures of behaviour take many forms (e.g. Martin \& Bateson 2007), behaviour can be well documented by assessment of move- ment, or the lack of it, which has been described by various animal-attached sensors (see Cooke et al. 2004 for review) including, recently, accelerometers (e.g. Yoda et al. 1999, Tanaka et al. 2001, Kato et al. 2006). Indeed, since accelerometers measure both animal orientation and the dynamics of movement (Yoda et al. 1999), animal-attached accelerometers can provide data on the occurrence of a wide range of behaviours in free-living organisms which cannot readily be observed (e.g. Watanabe et al. 2005, Tsuda et al. 2006, Wilson et al. 2008). 
As a consequence, accelerometry is a potentially powerful tool with which to address an array of conservation issues in higher vertebrates. For instance, behavioural data could be combined with information on animal location (Tanaka et al. 2001) to produce qualified maps of area-use, identified as a priority by Amlaner \& Macdonald (1980). Ultimately this could enable habitat to be delineated according to its importance for courtship, mating, the rearing of offspring, or any other behaviour identifiable in the species of interest. This approach could also be used to map the occurrence of particular behaviours, including those, such as the depredation of livestock, which are often a source of human-wildlife conflict (e.g. Marker et al. 2003). Accelerometry also has the potential to diagnose aberrant behavioural patterns, such as those associated with infection (Hart 1988). These patterns, whilst of interest per se, could also be combined with location information to provide insight into the source of the infection and the likelihood of transmission either within or between species (e.g. between the Eurasian badger Meles meles and cattle, Carter et al. 2007). The spread of disease is a central issue in the conservation of many higher vertebrates, particularly small populations, e.g. those of the Ethiopian wolf Canis simensis, which are susceptible to outbreaks of rabies following interactions with infected domestic dogs (Randall et al. 2006).

Despite the potential power of this technology and its use in fields such as veterinary and sport science (e.g. Cavagna et al. 1963, Barrey \& Desbrosse 1996), a relatively small number of people currently use accelerometry to investigate animal behaviour, and it has not yet, to our knowledge, been directly applied to animal conservation issues. In addition, the majority of deployments have been on aquatic organisms using mono- or bi-axial accelerometers (e.g. Watanuki et al. 2006, Sato et al. 2007). Acceleration can be measured in 3 axes (e.g. Wilson et al. 2008), which should be aspired to for a number of reasons: (1) This provides a measure of animal motion in all spatial dimensions, which gives a more accurate estimate of the animal's complete body acceleration with corresponding power to identify types of behaviour. While movement patterns such as locomotion are generally identifiable and quantifiable in 1 or 2 acceleration axes, other, rarer, movement patterns may only be identifiable by measuring acceleration in 3 axes. (2) Determination of the combined dynamic acceleration from 3 axes provides a proxy for energy expenditure (Wilson et al. 2006). (3) Proper quantification of the acceleration experienced by an animal's body in any axis necessitates that mono- and bi-axial accelerometers be aligned perfectly with the horizontal plane; however, where acceleration is measured in 3 axes, any reduction in measured accelera- tion in one axis is compensated for in other dimensions, so that device orientation on the animal is less critical. Finally, advances in solid-state technology mean that acceleration can now be measured in the third axis without increasing the size of the transducers or recording device.

The interpretation of animal acceleration data is complex, however, as measured acceleration is the result of both a static and a dynamic component (e.g. Sato et al. 2003) and animals can have a large repertoire of movement patterns that vary in duration and complexity. The aim of this study is to provide a general framework whereby the identification of movement patterns, as recorded by tri-axial accelerometers, could be simplified across animals of different body patterns and life-histories. Specifically, we seek to summarise the main principles of accelerometry, from the recorded data to initial transformations, and examine the potential of these outputs to offer insight into a range of biological questions. To this end, a range of animals of varying size and body patterns were equipped with tri-axial accelerometers. A subset of these animals was then observed in order to describe the accelerometric signals coding for the movement patterns recorded.

\section{MATERIALS AND METHODS}

Acceleration was recorded in 3 axes corresponding to the dorso-ventral, anterior-posterior and lateral axes (hereafter referred to as heave, surge and sway, which denotes the dynamic component in each respective axis) using experimental 'daily diary' (DD) units (Wilson et al. 2008). The DD circuitry was potted in epoxy resin (Atlas Polymers) and given a hydrodynamic shape. Units could record on up to 13 channels and included transducers for magnetic field strength in 3 axes, pressure, light and temperature; however, only the acceleration data are referred to here. Acceleration values are given in $g$, where $g$ represents acceleration due to gravity $\left(1 \mathrm{~g}=9.81 \mathrm{~m} \mathrm{~s}^{-2}\right)$. Tri-axial acceleration data were recorded with 22-bit resolution in a $128 \mathrm{Mb}$ flash RA memory with an accuracy of $\pm 0.06 \mathrm{~g}$. The units were programmed to record at up to $32 \mathrm{~Hz}$ using Terminal Freeware, and data were analysed using Origin Pro (OriginLab) and Microsoft Excel (Microsoft Corporation). A total of 12 animal species was instrumented with tri-axial accelerometers in both wild and captive conditions (Table 1); details of deployment are given below.

Field deployments. The recording devices used in field deployments were potted in resin, weighed $42 \mathrm{~g}$ in air and a maximum of $12 \mathrm{~g}$ in water, and had maximum dimensions of $55 \times 30 \times 15 \mathrm{~mm}$ unless otherwise 
Table 1. Summary of 'daily diary' deployments

\begin{tabular}{|c|c|c|c|c|}
\hline Common name & Latin binomial & Location & Co-ordinates & $\begin{array}{c}\text { Sampling } \\
\text { frequency }(\mathrm{Hz})\end{array}$ \\
\hline Eurasian badger & Meles meles & Wytham Woods, UK & $51^{\circ} 46^{\prime} \mathrm{N}, 1^{\circ} 18^{\prime} \mathrm{W}$ & 9 \\
\hline Imperial cormorant & Phalacrocorax atriceps & Punta León, Argentina & $43^{\circ} 04^{\prime} \mathrm{S}, 64^{\circ} 2^{\prime} \mathrm{W}$ & 8 \\
\hline Leatherback turtle & Dermochelys coriacea & St Croix, Carribean & $17^{\circ} 42^{\prime} \mathrm{N}, 64^{\circ} 52^{\prime} \mathrm{W}$ & 8 \\
\hline Lemon shark & Negaprion brevirostris & Bimini Island, Bahamas & $25^{\circ} 41^{\prime} \mathrm{N}, 79^{\circ} 17^{\prime} \mathrm{W}$ & 4 \\
\hline Magellanic penguin & Spheniscis magellanicus & Puerto Deseado, Argentina & $47^{\circ} 47^{\prime} \mathrm{S}, 65^{\circ} 53^{\prime} \mathrm{W}$ & 9 \\
\hline Cheetah & Acinonyx jubatus & Otjiwarongo, Namibia & $20^{\circ} 51^{\prime} \mathrm{S}, 16^{\circ} 38^{\prime \prime} \mathrm{E}$ & 32 \\
\hline Cheetah & Acinonyx jubatus & Gobabis, Namibia & $21^{\circ} 43^{\prime} \mathrm{S}, 19^{\circ} 20^{\prime} \mathrm{E}$ & 32 \\
\hline Coypu & Myocastor coypus & Buenos Aires Zoo, Argentina & $34^{\circ} 36^{\prime} \mathrm{S}, 58^{\circ} 22^{\prime} \mathrm{W}$ & 32 \\
\hline Brazilian tapir & Tapitus terrestris & Buenos Aires Zoo, Argentina & $34^{\circ} 36^{\prime} \mathrm{S}, 58^{\circ} 22^{\prime} \mathrm{W}$ & 32 \\
\hline Giant ant-eater & Myrmecophaga tridactyla & Buenos Aires Zoo, Argentina & $34^{\circ} 36^{\prime} \mathrm{S}, 58^{\circ} 22^{\prime} \mathrm{W}$ & 32 \\
\hline Guanaco & Lama guanicoe & Buenos Aires Zoo, Argentina & $34^{\circ} 36^{\prime} \mathrm{S}, 58^{\circ} 22^{\prime} \mathrm{W}$ & 32 \\
\hline Hairy armadillo & Chaetophractus villosus & Buenos Aires Zoo, Argentina & $34^{\circ} 36^{\prime} \mathrm{S}, 58^{\circ} 22^{\prime} \mathrm{W}$ & 32 \\
\hline Mouflon & Ovis musimon & Buenos Aires Zoo, Argentina & $34^{\circ} 36^{\prime} \mathrm{S}, 58^{\circ} 22^{\prime} \mathrm{W}$ & 32 \\
\hline Llama & Lama glama & Buenos Aires Zoo, Argentina & $34^{\circ} 36^{\prime} \mathrm{S}, 58^{\circ} 22^{\prime} \mathrm{W}$ & 32 \\
\hline
\end{tabular}

stated. Imperial cormorants Phalacrocorax atriceps, with a mean body mass of $2.1 \mathrm{~kg}$ (Svagelj \& Quintana 2007), were the smallest species equipped - as such, the device represented an average $2 \%$ of the animal's mass in air.

Thirty-three imperial cormorants were instrumented in Punta León, Argentina (Table 1) in December 2005 and 2006, using a custom-made crook to remove birds from the nests where they were brooding chicks. The devices were attached to the lower back using Tesa tape (Wilson et al. 1997) before birds were returned to their nests, where they continued brooding. The whole procedure took $<5$ min. Twenty-one Magellanic penguins Spheniscus magellanicus were caught and equipped with a DD in Puerto Deseado, Argentina (Table 1), during December 2005 and 2006, using Tesa tape to attach the units, and the handling method outlined in Wilson et al. (1997). These birds were also brooding small chicks and were returned to the nest after $<5$ min of handling time. Birds from both species were allowed to forage for a single trip before the devices were retrieved.

Three Eurasian badgers Meles meles were equipped with data loggers in Wytham Woods, UK (2004), after being trapped and sedated following the methods specified by Macdonald \& Newman (2002). The DD was attached to a leather collar using duct tape and fastened round the animals' necks. The procedure took ca. $5 \mathrm{~min}$. The badger was released following recovery from the sedative and recaptured after 2 to $95 \mathrm{~d}$ to retrieve the devices.

Four female leatherback turtles Dermochelys coriacea were equipped with DDs at St Croix, Caribbean (Table 1), during the inter-nesting period in May 2007. Individuals were equipped and devices were retrieved when turtles exited the water to lay eggs. Loggers (dimensions $120 \times 20 \times 35 \mathrm{~mm}$, mass $90 \mathrm{~g}$ ) were attached directly to the central dorsal ridge of the carapace (Fossette et al. 2008) by feeding $2 \mathrm{~mm}$, coated stainless steel wire through 2 holes in the ridge, ca. $6 \mathrm{~cm}$ apart, and crimping them together into 2 loops around the device and its base. The base of the device was constructed from Platinum Silicone Putty (Equinox TM Series; www.smooth-on.com) to form a streamlined and snug fit to the top of the central ridge of the animal. Deployment lasted from $4.5 \mathrm{~h}$ to $7.3 \mathrm{~d}$.

Captive deployments. Deployments on captive animals were mainly made in Buenos Aires Zoo, Argentina (Table 1), during May 2007, using resin-potted devices measuring $65 \times 36 \times 15 \mathrm{~mm}$, mass $21 \mathrm{~g}$. The smallest animal to be instrumented was a hairy armadillo Chaetophractus villosus, which had a body mass of $2.98 \mathrm{~kg}$ and where the device represented $0.7 \%$ of the animal's mass. Animals were captured and restrained by the zoo keepers, without sedative, with a handling time of less than ca. 6 min for any individual. A vet was present during the capture of each animal. Devices were attached for relatively short periods of time ( 77 to $126 \mathrm{~min}$, mean $110 \mathrm{~min}$ ) during which time the animals were released into their pens, where they were observed, and patterns of movement and behaviour were recorded.

Nominally, devices were attached using a collar constructed from Silastic P1 ${ }^{\circledR}$. Silastic is a highly elastic, soft, hypoallergenic 2-part silicone-based rubber (Dow Corning; UK supplier: W. P. Notcutt, Ripley), which was poured into a mould to create strips, ca. $3 \mathrm{~mm}$ thick at their widest point, which could be cut to appropriate lengths and fastened around the animal's neck with a cable tie so that they were fitted flush against the skin. The device was attached to the collar using Tesa tape and was positioned on the ventral side of the animal's neck. The animals showed no signs of discomfort due to the attachment of the device apart from the 
Brazilian tapir, which shook its head sporadically, possibly in response to the position of the Silastic collar, which was wrapped over its head in an effort to keep the device dry. Otherwise, a single device was attached to a female hairy armadillo Chaetophractus villosus using Tesa tape to secure it to the armour just behind the back of the neck, and a single device was also attached to a male mouflon Ovis musimon using a leather collar.

Devices were also deployed in April 2007 on 5 semitame cheetahs Acinonyx jubatus in rehabilitation facilities at Africat, Otjiwarongo, Namibia, and at Harnas, Gobabis, Namibia. Four deployments were made at Africat; 2 on habituated animals without the need for sedative, and 2 on unhabituated animals that were captured with a dart rifle with a combined dose of Zolatil and Medetomidine, and recaptured using a dose of Ketamine. Devices were attached to leather collars, and instrumented animals were allowed to roam freely in large enclosures (400 and 4000 ha at Africat) for the duration of the deployment (range 4 to $7 \mathrm{~d}$ ).

Two lemon sharks Negaprion brevirostris, of total lengths 186 and $150 \mathrm{~cm}$, were captured in April 2006 off Bimini Island, Bahamas (Table 1). Animals were captured using sport-fishing gear with Mustad shark size 10 circle hooks baited with live bait from a small skiff, while the water was chummed. Once captured, the sharks were transported in large water containers onboard the boat, to an oval pen (ca. $20 \times 5 \mathrm{~m}$ ) situated within an otherwise open lagoon, where the animals were left to rest for a minimum of $2 \mathrm{~d}$ before trials commenced. Each shark was instrumented by guiding it into a polyurethane sling using a hand-held seine-net and large wooden boards, where the devices were attached (dimensions $90 \times 32 \times 20 \mathrm{~mm}$, mass $60 \mathrm{~g}$ in air) by passing 2 sections of monofilament line through the device and the dorsal fin. After periods of 2 and $4 \mathrm{~d}$, respectively, subjects were recaptured using the same method as that preceding instrumentation and the device was removed by cutting the monofilament with wire cutters prior to the sharks being released.

Analysis. Dynamic acceleration was derived in the Magellanic penguin data by taking a running mean of total acceleration values over $2 \mathrm{~s}$ (Wilson et al. 2006). All other manipulations are described below.

Total acceleration values in one channel were found to contain system noise for deployments on the guanacos and leatherback turtles. Increases in acceleration that did not accord with changes in acceleration due to body motion were removed from these channels, identified as data points $>0.4 \mathrm{~g}$ different to the previous data point in the channel measuring sway acceleration in the guanaco, and data points differing by $>0.2 \mathrm{~g}$ from the previous data point in the channel measuring surge acceleration in the leatherback turtle data.

\section{RESULTS AND DISCUSSION}

Total acceleration values, that is, the raw acceleration values recorded in each acceleration channel, include both a static and dynamic component that can be used to determine animal posture and movement. The following sections describe how these data can be used separately and in tandem to recreate movement patterns, either as a descriptive exercise (for instance, where the pattern has not been previously documented), or to ascribe a possible function where the movements are consistent with a known behaviour. The biomechanical processes underlying movements such as locomotion are described extensively elsewhere (e.g. Alexander 1983, Schmidt-Nielsen 1997) and are alluded to here in the context of the associated patterns in acceleration and their relevance to the identification and study of animal behaviour. The power to resolve such patterns may depend on both the sampling frequency and the method used to attach the device to the animal because loose attachments, such as some collar fittings, will generate noise as the animal moves.

\section{Static acceleration}

Static acceleration is a measure of the incline of the accelerometer with respect to the earth's gravitational field and therefore provides a measure of the body angle of the instrumented animal. Static acceleration measured in 3 axes enables the calculation of body pitch and roll (Wilson et al. 2008, their Fig. 5b). The pitch is calculated as the arcsine of $g$, where $g$ is the static acceleration in the heave channel. The roll is derived in the same way from the static acceleration in the sway axis. Static acceleration ranges from 1 to $-1 \mathrm{~g}$ in each channel, each sensor recording its maximum of $1 g$ when facing upwards, directly away from the earth's gravitational field (e.g. Fig. 1a).

The sensitivity with which the device measures changes in pitch will vary with device angle because body angle is an arcsine function of the static component (Fig. 1). Pitch can be derived from both the surge and heave, and in an upright, stationary animal, the heave measures $1 \mathrm{~g}$ and the surge $0 \mathrm{~g}$. If, however, the animal rotates forward by $40^{\circ}$ for example, the change in $g$ from the channel measuring surge (given as $y$ in Fig. 1a) becomes proportionately greater than that measured by the heave (given as $x$ in Fig. 1a) due to the changing function of the arcsine of the measured $g$. Generally, the surge is more sensitive to changes in pitch at body angles of 0 to $45^{\circ}$ and 135 to $180^{\circ}$ (Fig. 1b) and the heave more sensitive to changes in pitch at body angles of 45 to $135^{\circ}$ (Fig. 1b). 

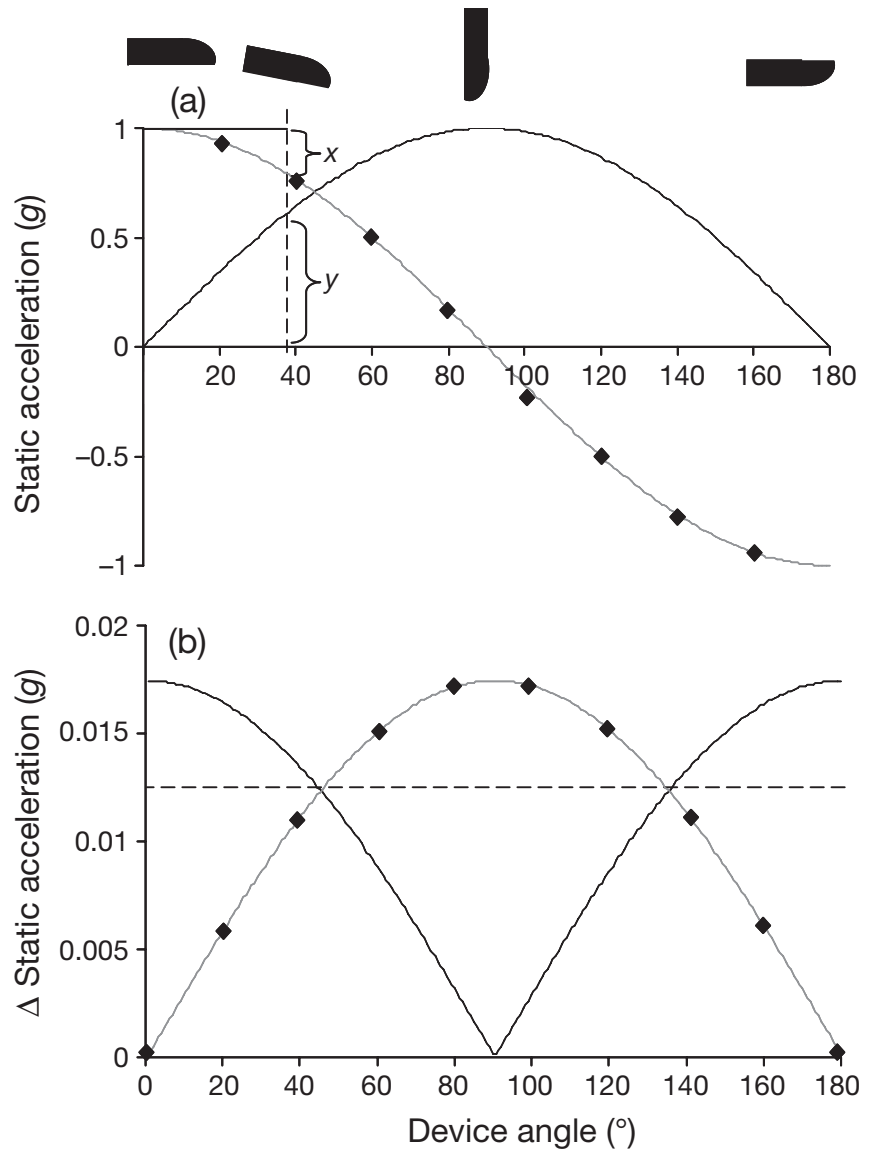

Fig. 1. (a) Relationship between static acceleration and body angle for channels measuring heave and surge. Position of the device shown above the graph. In initial position, static acceleration in the heave axis is shown as $(\neg-)$, and surge as (-). After movement of the device through some $40^{\circ}$, shown by the dashed line, the change in surge $(y)$ is greater than the change in heave $(x)$. (b) Rate of change in static acceleration

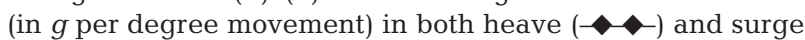
(-) is plotted against body angle, where lines above the horizontal dashed line indicate when each of the axes is most sensitive to changes in body angle pitch

Since pitch is derived from the static acceleration, this component needs to be derived from the total acceleration, which includes both static and dynamic acceleration. Static acceleration may be derived by subjecting the total acceleration to an appropriate pass filter (e.g. Tanaka et al. 2001, Watanuki et al. 2005) or, as for this work, by smoothing (Yoda et al. 2001, Wilson et al. 2008) before converting the resultant value into degrees using the arcsine function (Fig. 2a). It is thus possible to estimate the approximate body pitch and roll angle of animals by simple visual inspection of the total acceleration data (Fig. 2a), assuming that the device is aligned perfectly with the horizontal plane. We note that imperfect orientation of the device on the animal will result in pitch angles offset from the ani-
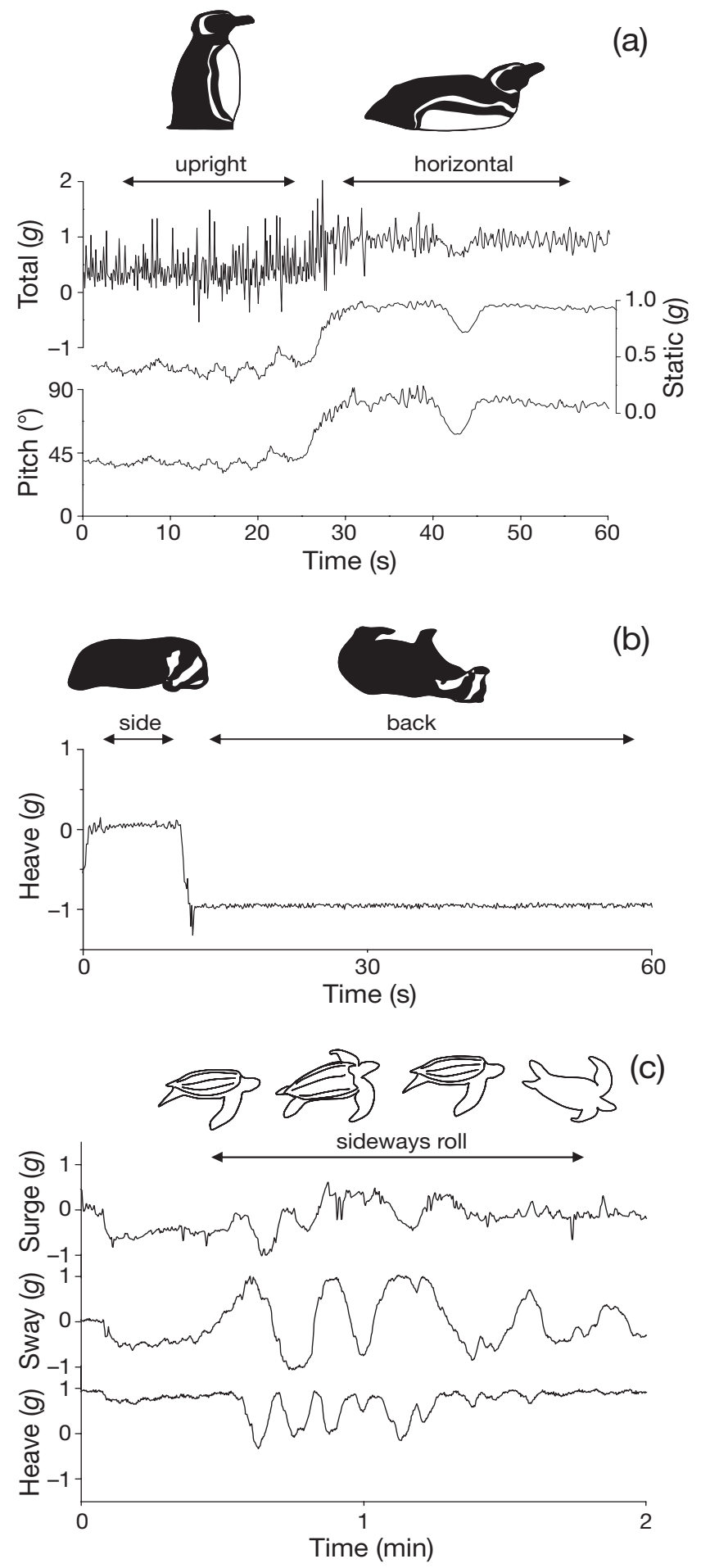

Fig. 2. Spheniscus magellanicus, Meles meles and Dermochelys coriacea. (a) Body pitch of a Magellanic penguin, which is apparent as the mean value of the total heave acceleration (top plot), derived static acceleration from the heave axis (middle plot) and body pitch in degrees (lower plot). (b) Total heave acceleration from a Eurasian badger as it moved from lying on its side to lying on its back. (c) A leatherback turtle, where rotations through $90^{\circ}$ in the heave axis and simultaneous rotations through $180^{\circ}$ in the sway axis describe a rolling manoeuvre that almost involved complete inversion 
mal's longitudinal axis to a corresponding degree. We refer to such deviations as the 'device angle' (following notation by Watanuki et al. 2003). This device angle must be accounted for in the calculation of real animal pitch, and can be best calculated when the animal is either horizontal or perpendicular, as recorded during instrumentation or when the animal is ranging freely (Watanuki et al. 2003). If the method of device attachment allows for some movement, e.g. if the device is attached using a leather collar, the device angle may change during the deployment and need re-calibrating. For simplicity, in further discussion of predicted static values it is assumed that the device angle is equal to $0^{\circ}$.

The identification of body pitch and roll is an important step in the classification of animal movement patterns (Watanabe et al. 2005) as any body posture will narrow the range of possible behaviours or be characteristic of one behavioural pattern for the study animal in question. In the first instance, body posture can be useful at a broad scale. For instance, a penguin that is upright for minutes or hours can only be on land, whereas a penguin in a horizontal position can be either on land (in which case it is likely to be resting) or in water (and therefore swimming), Fig. 2a (see also Ropert-Coudert et al. 2006). An upright posture in a meerkat Suricata suricatta, however, is indicative of vigilant behaviour (Clutton-Brock et al. 1999) and would therefore record variance in vigilance through time, whereas in felids, an upright posture is likely to occur against a support, for instance during climbing or claw sharpening (e.g. Watanabe et al. 2005). For many mammals, maintaining a position on their back or side is likely to be indicative of rest or sleep (Fig. 2b). Postural data can therefore be used to determine the amount of time an animal rested, even while underground, when the relative activity of animals such as badgers is unknown, or whether the proportion of rest is unusually high, such as may be symptomatic of infection (Hart 1988).

Cognisance of the length of time that a particular body posture is adopted is also important as, over short intervals, body posture sequences can be indicative of behavioural patterns. For instance, during a dive, an air-breathing vertebrate has a characteristic angle of descent (according to dive depth, e.g. Wilson et al. 1996), after which there may be a bottom phase and associated horizontal posture (e.g. in imperial cormorants, Gómez Laich 2008, this Theme Section) before the body is pointed toward the surface for the ascent (e.g. Wilson et al. 1996). In Magellanic penguins this sequence may take up to 276 s (Walker \& Boersma 2003). Other, more transient behaviours may also involve a conserved sequence of body postures, such as the scent-marking squat in badgers (Buesching \& Macdon- ald 2004). Other parameters include the range of angles through which the animal move, the speed of change and/or the presence of repetition or rhythm in the changes. Changes in posture may occur in one or both planes, for instance a leatherback turtle Dermochelys coriacea rolled repeatedly $180^{\circ}$ to one side and then $180^{\circ}$ to the other (Fig. 2c), a pattern that almost describes a barrel roll (and distinguished from it by changes in the heave axis, which did not show a continuous rotation in one direction). In this case, dramatic changes in body posture occurred with little dynamic acceleration, so the behaviour could only be identified using the static component of acceleration. Movement also occurs with little dynamic acceleration during gliding and soaring flight (cf. Pennycuik 1972) as well as in aquatic animals, where gliding occurs during dive descents in negatively buoyant species such as flounders (Kawabe et al. 2003a) and in dive ascents in positively buoyant species (Sato et al. 2002). While passive dive descents are likely to be characterised by particular body angles, others, notably dynamic soaring, are characterised by sequential changes in body posture (Nelson 1980, and see Wilson et al. 2008, their Fig. 7).

While static acceleration can characterise some behaviours, animals often have 1 or 2 predominant postures, such as the horizontal stance in tetrapod mammals, during which a diverse range of behaviours are performed. In such cases, beyond static acceleration, patterns of dynamic acceleration can provide detailed information to help identify these behaviour patterns.

\section{Dynamic acceleration}

\section{Locomotion}

The dynamic component of total acceleration represents the change in velocity as a result of body motion. It can be derived in its simplest form by subtracting the static acceleration values (attained, for example, via smoothing) from the total acceleration values over this time period (Wilson et al. 2006). According to Newton's third law, which states that for every action there is an equal and opposite reaction, the movement of a limb in one direction will produce an opposite movement in the trunk. This is apparent in repetitive movement patterns during locomotion (Fig. 3), where the movement of a limb during a power stroke results in a movement of the body in the other direction. For instance, a wingstroke downwards (movement in the heave axis) will result in an acceleration (and therefore movement) of the body upwards (Fig. 3a) (cf. Kato et al. 2006), the lateral motion of a fish tail in one direction will move the body in the other (Fig. 3b) (cf. Kawabe et al. 2003b), 

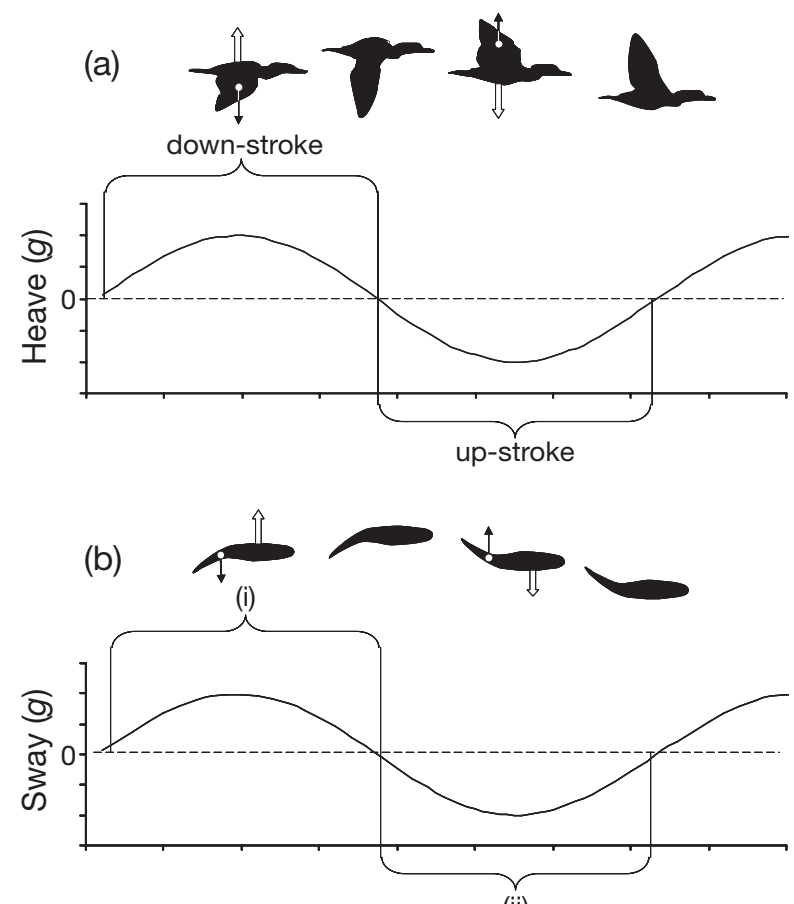

(ii)

(c)
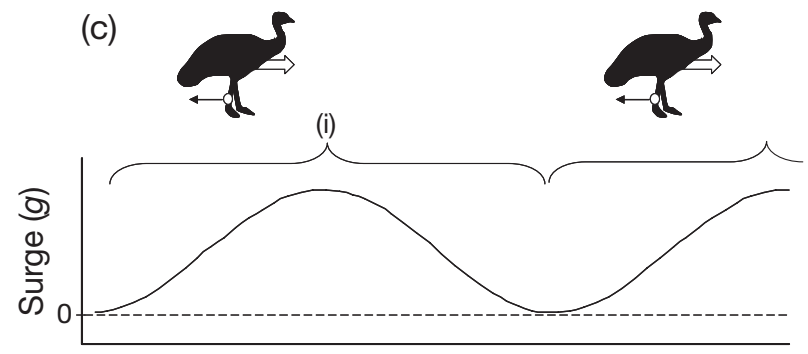

Fig. 3. Schematic changes in dynamic acceleration arising from locomotive limb movements in 3 different axes: (a) heave, as expected during flapping flight, (b) sway during carangiform swimming, and (c) surge during bipedal walking. Block arrows on the animals indicate the direction of body movement, while the single line arrows show the direction of limb movement. In (b) the 2 parts of the stroke cycle are indicated as (i) and (ii), whereas in (c) one full stroke cycle is shown as (i)

and the movement of a limb backwards against the substrate will propel the body forwards (Fig. 3c). Note that in fish, whether the measured acceleration in the trunk is opposed to that of the tail will depend largely on the position of the recording device.

Oscillations in dynamic acceleration are characteristic of locomotion across animals of different body patterns (Fig. 4). At points of zero dynamic acceleration, the total acceleration is equal to the static acceleration. When dynamic acceleration is a component of total acceleration, changes in dynamic acceleration are recorded in relation to the static value and, therefore, both increasingly positive and increasingly negative values of $g$ can represent an increase in dynamic accel- eration. For instance, in a carangiform swimmer the value of sway will be zero at rest. Each stroke cycle includes 2 power-strokes as the tail moves first to one side and then the other (Fig. $3 \mathrm{~b}-\mathrm{i}$ and ii, respectively, Fig. 4f). The first tail movement causes an increase in sway acceleration, which is followed by a momentary decrease (Fig. 3b-i) before sway acceleration is produced by the tail moving in the opposite direction (Fig. 3b - ii), which then also subsides (Ogilvy \& Dubois 1981, Kawabe et al. 2003b). Here, the negative acceleration stemming from the second tail movement is a reflection of the output of the sway transducer and is only negative with respect to the direction of the acceleration produced during the first tail movement. In contrast, increases in surge acceleration occur mainly in a forward direction and are therefore recorded in one direction from the static acceleration value, as is apparent in heave acceleration during walking (Figs. 3c \& 4a,b) and described for the propulsive underwater kicks of a cormorant (Kato et al. 2006). These 2 contrasting patterns are evident in the acceleration signal from a walking penguin (Fig. 4e), where values of sway show peaks above and below a mean of zero, but both these peaks are represented by increases in surge from a baseline of zero.

The ability to identify locomotion has broad ecological applications. For instance, temporal patterns in locomotion can provide insight into changes in behavioural rhythms such as are seen during the onset of migration (Tanaka et al. 2001, Bolger et al. 2008), and in response to environmental change (Tsuda et al. 2006). The proportion of time an individual spends in locomotion can also provide important insights into the way it uses its environment, for instance, the distance and effort required to access a particular resource. The extent of locomotion can provide a measure of distance moved when stride frequency is combined with stride length (Alexander 1983). The need to travel further or search for longer, in order to feed or provision young, may give an early indication that individuals are under environmental stress (Gremillet et al. 2006). Such information may not be available from positional data alone, for instance, in animals that also move in the vertical dimension. The relative efficiency of resource acquisition is also affected by the effort invested in locomotion per unit time. Animal-borne accelerometers are well-placed to measure this, as the combined dynamic acceleration from 3 axes, known as the overall dynamic body acceleration (ODBA), has been shown to correlate well with energy expenditure in a range of species (Wilson et al. 2006, 2008, Halsey et al. in press). Information on effort can also be gleaned from the gait and relative speed at which individuals travel, and these parameters are also identifiable in acceleration data, as discussed below. 

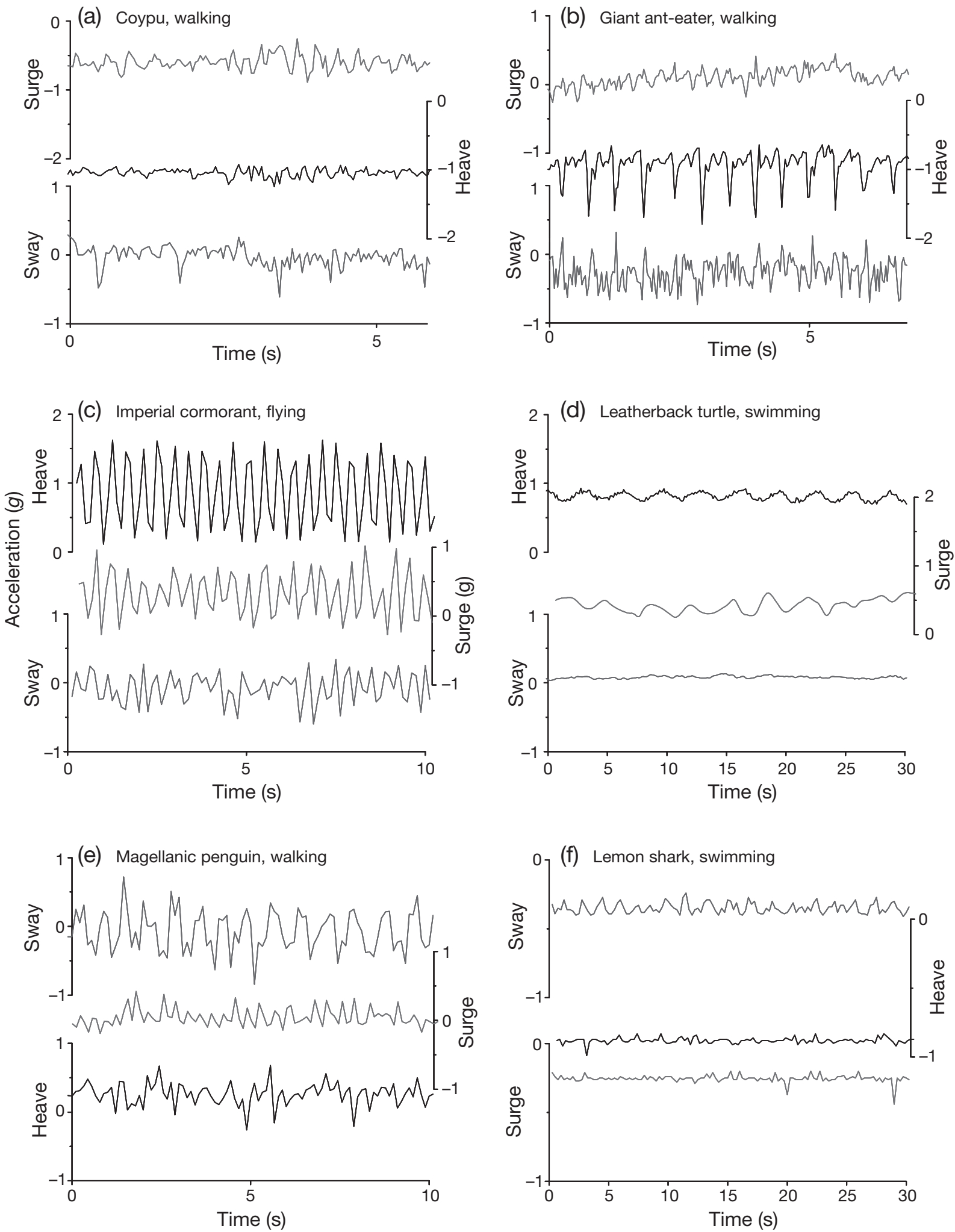

Fig. 4. Total acceleration across a range of animals and types of locomotion as listed above each plot, with time on the $x$-axis, and showing surge, heave and sway (note the different axis labels). The plots are paired according to the main axis of limb movement during locomotion, with limbs moving $(a, b)$ in the surge axis during walking, $(c, d)$ in the heave axis during flight and swimming and (e,f) in the sway axis in walking and swimming. Within each plot, the axes are ordered according to the general strength of the acceleration signal. All $y$-axes have a range of $2 g$ except that for the lemon shark, where the range is $1 g$ 
Although relatively complex techniques such as the fast Fourier transform (e.g. Watanabe et al. 2005), band-pass filters and shape analysis (Schreer \& Testa 1995) can be applied to describe these patterns, simple rules define expected patterns across and within species (Table 2). Generally, the axis in which the limbs move shows the largest variation in acceleration, this equating predominantly to either heave or sway (Table 1). Acceleration in the surge axis will tend to show smaller fluctuations even where limbs move in this axis (e.g. during walking) as it is more efficient to travel at a relatively constant velocity, with minimal deceleration between power strokes (Schmidt-Nielsen 1997). A switch from one predominant axis to another typifies a change in the type of locomotion. For instance, walking in a cormorant is characterised by oscillations around $0 \mathrm{~g}$ in the sway (similar to the pattern shown by walking penguins; Fig. 4e), whereas flight is typified by oscillations in the heave around a mean of $1 \mathrm{~g}$ (Fig. 4c, see also Gómez Laich 2008). During terrestrial tetrapod locomotion, the heave axis may show regular acceleration 'spikes' caused by the animal pushing against a hard substrate, as can be seen during a giant ant-eater walking (Fig. 4b).

Similarities in acceleration arising from locomotion between animals with comparable body patterns are expected. In the tetrapod mammals equipped, walking was typified by the strongest changes in acceleration in the heave axis (cf. above), with increases from a baseline value of $1 g$ (Fig. 5). Typically, each peak in heave had a slight dip in it, giving a characteristic ' $\mathrm{m}$ ' shape, more evident at higher speeds (Fig. 6). Rhythmic peaks were also evident in the surge, with 2 peaks for every increase in heave (Fig. 5), but less clear in the sway axis. These types of similarities in patterns of acceleration across species with different body types and gaits (e.g. knuckle-walking in the giant anteater versus digitigrade quadrupedalism) may aid the development of automated pattern-recognition, and the use of patterns known in one species, for the recognition of those as yet not described in others, particularly where the undescribed species has a body plan that conforms roughly to that of a described animal.

Dynamic acceleration also changes substantially with changes in patterns of locomotion within individuals. Here, an increase in the frequency and/or amplitude of changes in acceleration is indicative of an increase in effort and usually, speed (Alexander 1983). Accelerometers may therefore provide a good estimate of an animal's speed of locomotion, through the frequency (e.g. Herren et al. 1999, Kawabe et al. 2003b), amplitude and pattern of changes in locomotion in 1 or 2 axes, or the combined dynamic acceleration from 3 axes, which predict speed accurately in humans (Halsey et al. in press). An animal's speed of movement is a difficult parameter to measure (Ponganis et al. 1990, Sato et al. 2007, Shepard et al. 2008), particularly in terrestrial species (Jedrzejewski et al. 2001). Nonetheless, it is a key variable modulating animal behaviour, as it is a strong determinant of an animal's energy expenditure (Taylor et al. 1982, SchmidtNielsen 1997), particularly in the aquatic environment,

Table 2. Predicted strength of total heave, sway and surge accelerations in example vertebrates locomoting through different media. Patterns where acceleration is primarily generated by the down-stroke are denoted $\left({ }^{*}\right)$; here measured increases in heave will be asymmetrical around the mean

\begin{tabular}{|c|c|c|c|c|c|c|c|}
\hline \multirow[t]{2}{*}{ Medium } & \multirow[t]{2}{*}{ Locomotion } & \multirow[t]{2}{*}{ Gait } & \multirow[t]{2}{*}{ Taxon } & \multicolumn{3}{|c|}{ Strength of oscillations } & \multirow[t]{2}{*}{ Pattern in primary axis } \\
\hline & & & & Heave & Sway & Surge & \\
\hline \multirow[t]{4}{*}{ Water } & Rear propulsion & Swimming & Salmon & Minimal & Strong & Little & Fig. 3b \\
\hline & Rear propulsion & Swimming & Crocodile & Minimal & Strong & Little & Fig. 3b \\
\hline & Front propulsion & Swimming & Penguin & Strong & Minimal & Little & Fig. $3 \mathrm{~b}$ \\
\hline & Front propulsion & Swimming & Turtle & Strong & Minimal & Little & Fig. 3b \\
\hline \multirow{4}{*}{ Land } & Tetrapod & Walking & Llama & Strong & Minimal & Little & Fig. $3 c^{*}$ \\
\hline & Bipod & Waddle & Duck & Little & Strong & Little & Fig. 3b \\
\hline & Tetrapod & Hopping & Rabbit & Strong & Minimal & Strong & $*$ \\
\hline & Bipod & Jumping & Kangaroo & Strong & Minimal & Strong & \\
\hline \multirow[t]{3}{*}{ Air } & Flight & Flapping & Pigeon & Strong & Minimal & Little & Fig. $3 a^{*}$ \\
\hline & Flight & Gliding & Buzzard & Sporadic & & & \\
\hline & Flight & Soaring & Buzzard & Sporadic & & & Irregular, due to thermals \\
\hline
\end{tabular}



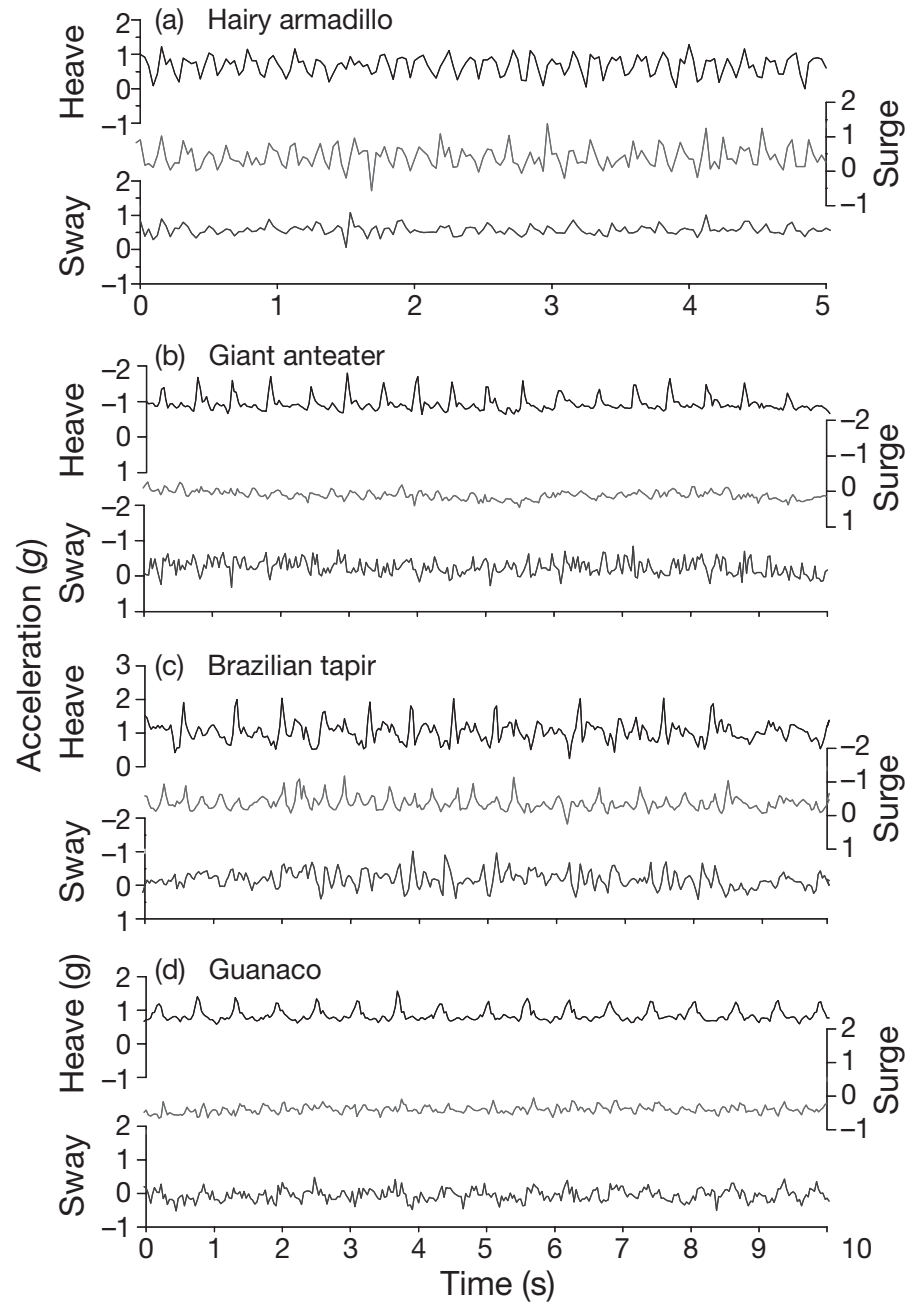

Fig. 5. Chaetophractus villosus, Myrmecophaga tridactyla, Tapitus terrestris and Lama guanicoe. Total acceleration (in $g$ ) in 4 species of tetrapod during walking. Heave, surge and sway are shown where energy expenditure increases as an exponential function of speed (e.g. Culik et al. 1994).

Changes in the frequency and amplitude patterns seen in accelerometric signals may be accompanied by an identifiable change in gait (Zijlstra 2004, Watanabe et al. 2005). For instance, a llama increasing its speed from walking to running showed changes in stride frequency from 1.63 to 1.78 to 1.75 strides per second (Fig. 6). The decrease in stride frequency (following the initial increase) reflected a change in gait as the animal started cantering (as noted during concomitant observations), which is associated with an increase in stride length as well as acceleration per stride (Alexander 1983). The pattern of acceleration per stroke cycle also changed as the effort increased: the acceleration resembled a smooth sine wave during walking, with the waveforms in all axes having the same period (Fig. 6), but as effort increased, the amplitude of the peaks in acceleration and the frequency of the strokes increased, and the pattern of acceleration in the sway axis became desynchronised with the other 2 axes. A small decrease also appeared in the middle of each acceleration peak in the heave and surge (Fig. 6), likely to represent the movement of 2 pairs of legs in unison per stride, which is the 2-beat gait characteristic of trotting (Alexander 1984). As the llama increased its speed further, each main peak was followed by a subsidiary peak, which may reflect the '3-beat gait' of cantering in camelids (Alexander 1984). Here, patterns of acceleration in all 3 dimensions changed with the animal's gait. Such changes can form the basis for quantifiable classification of different movement patterns where conserved across individuals (e.g. Tsuda et al. 2006).

The effort associated with movement can provide a measure of the animals' motivation and therefore
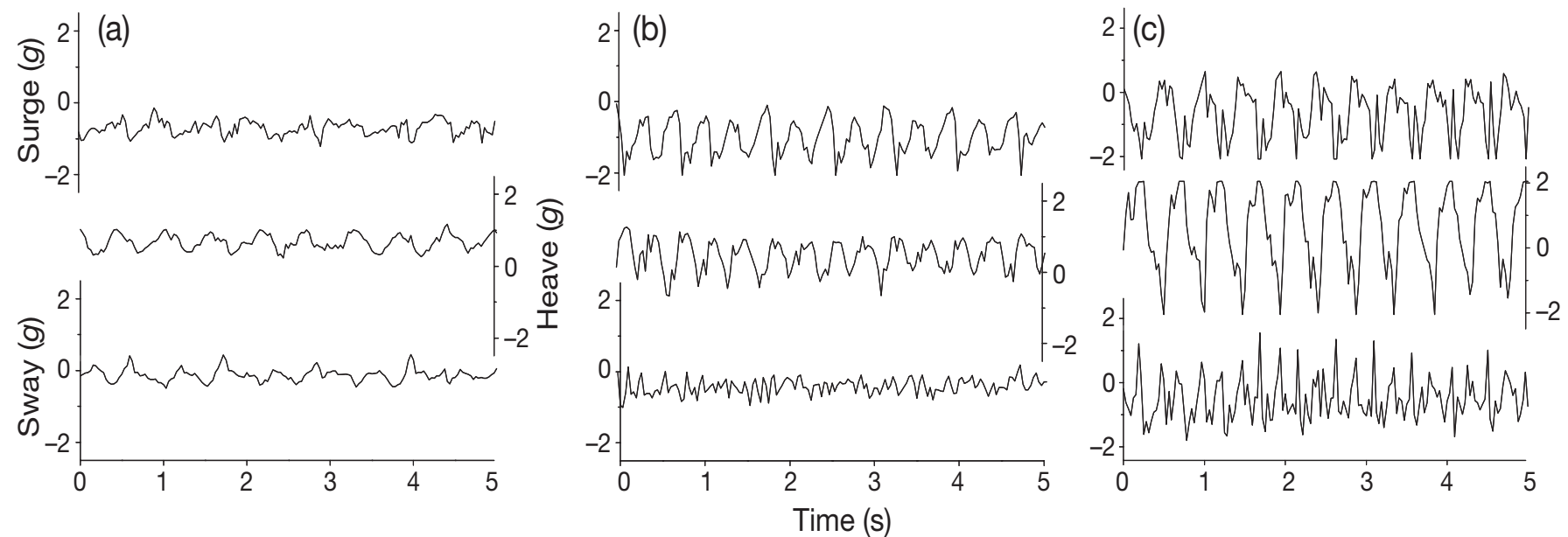

Fig. 6. Lama glama. Total acceleration (in g) for a llama while (a) walking (b) walking at increased speed or (c) running 
insight into the function of a movement pattern. For instance, animals are expected to travel at a speed that minimizes the cost of transport (e.g. Culik et al. 1994), which is likely to correspond to the predominant frequency in acceleration data through time (Sato et al. 2007). Lower frequencies will arise when the purpose of locomotion is not to minimize net energy used per unit distance travelled, e.g. optimizing food intake while grazing. Higher frequencies and amplitudes occur when an animal is being pursued or in pursuit of another (Wilson et al. 2002). Behaviours with motivation more complex than the minimization of the cost of transport are likely to be identifiable by further characteristics in acceleration data.

\section{Movement other than locomotion}

The identification of movement patterns from behaviours other than locomotion is more complex, and more likely to involve patterns of acceleration in all 3 axes, yet the principles remain the same. Identifying the diversity of an animal's behaviours could be important, for instance, where a lack of variability is a diagnostic feature of infection (Hart 1988), or symptomatic of resource absence. There is the potential to identify any pattern of behaviour where it is represented by a conserved posture and/or motion. Less common behaviours may also be identified by their position in a sequence of known behavioural patterns. For instance, in rutting male mountain goats, a mutual clash/headbutt is preceded by a run-up or charge (McClelland 1991), which is manifest as a run followed by abrupt peaks in all acceleration axes indicating a substantial impact (cf. our Fig. 7, and compare to the impact expe-

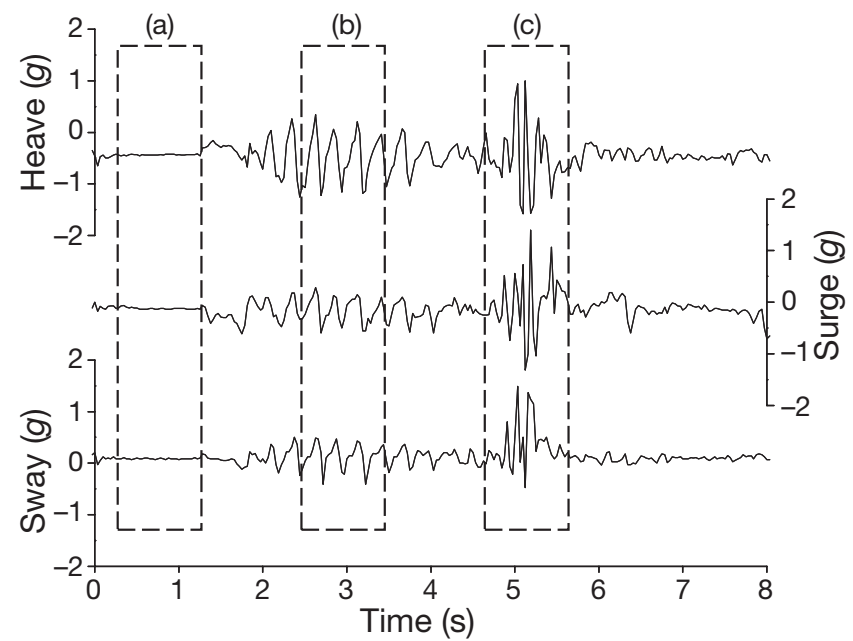

Fig. 7. Ovis musimon. Total acceleration (in $g$ ) for a male mouflon whilst (a) motionless (b) charging or (c) head-butting another male rienced by a gannet during a plunge dive, RopertCoudert et al. 2004). In the case recorded by our study shown in Fig. 7, the impact of the head-butt was likely to be much greater than that recorded, with some of the impact being absorbed by specially-adapted tissue in the head (Currey 1984) dissipated along both the neck and the collar attachment of the device, which was not tight against the animals' skin.

In practice, the static and dynamic components are likely to be interpreted in tandem, with one component being used to contextualise the other (Fig. 8). For instance, for grazing herbivores, including many ungulates and camelids, body posture is indicative of feeding behaviour, with head down during ingestion and head up during mastication and when moving between food patches. Such patterns can be identified in acceleration traces, particularly where the device is attached to a collar and therefore sensitive to changes in position of the neck (Fig. 8a,b), and could enable the quantification of the time allocated to ingestion. Feeding may also be identified in other animals, as prey capture attempts often form part of a relatively conserved behavioural sequence, such as predators that pursue prey (Fig. 9) (Watanabe et al. 2005). Prey handling may also be identifiable to confirm when chases were successful. A diverse range of behaviours could be identified through the combination of static and dynamic elements; for instance, washing behaviour was apparent in a cormorant as brief bouts of flapping with the bird in a horizontal posture, followed by a 'ducking' change in posture before the end of the bout (Fig. 8c,d). Digging and shaking are also likely to produce distinctive acceleration patterns. Software is currently being constructed that enables the visualisation of body posture and motion, as measured on the instrumented animal, to facilitate the identification of behaviours, even those as yet undescribed. The scale at which behaviour can be recognised (either visually or through the use of pattern recognition software) is likely to be improved by the combination of acceleration signals with visual observations. This may ultimately enable researchers to distinguish patterns such as those associated with the selection of food type, thus enabling the calculation of net energy gain per unit time, even in taxa with characteristically variable diets.

In summary, animal-attached accelerometers can be used to identify a wide range of behaviour patterns by providing quantitative data on body posture and motion. This yields data on the occurrence and intensities of behaviour with excellent resolution. Clues to the possible function of such behaviour patterns may also be available from the time they occurred or the sequence of behavioural changes. Furthermore, such data may be used to allude to activity-specific metabolic rate, where recorded in 3 axes. This requires a 

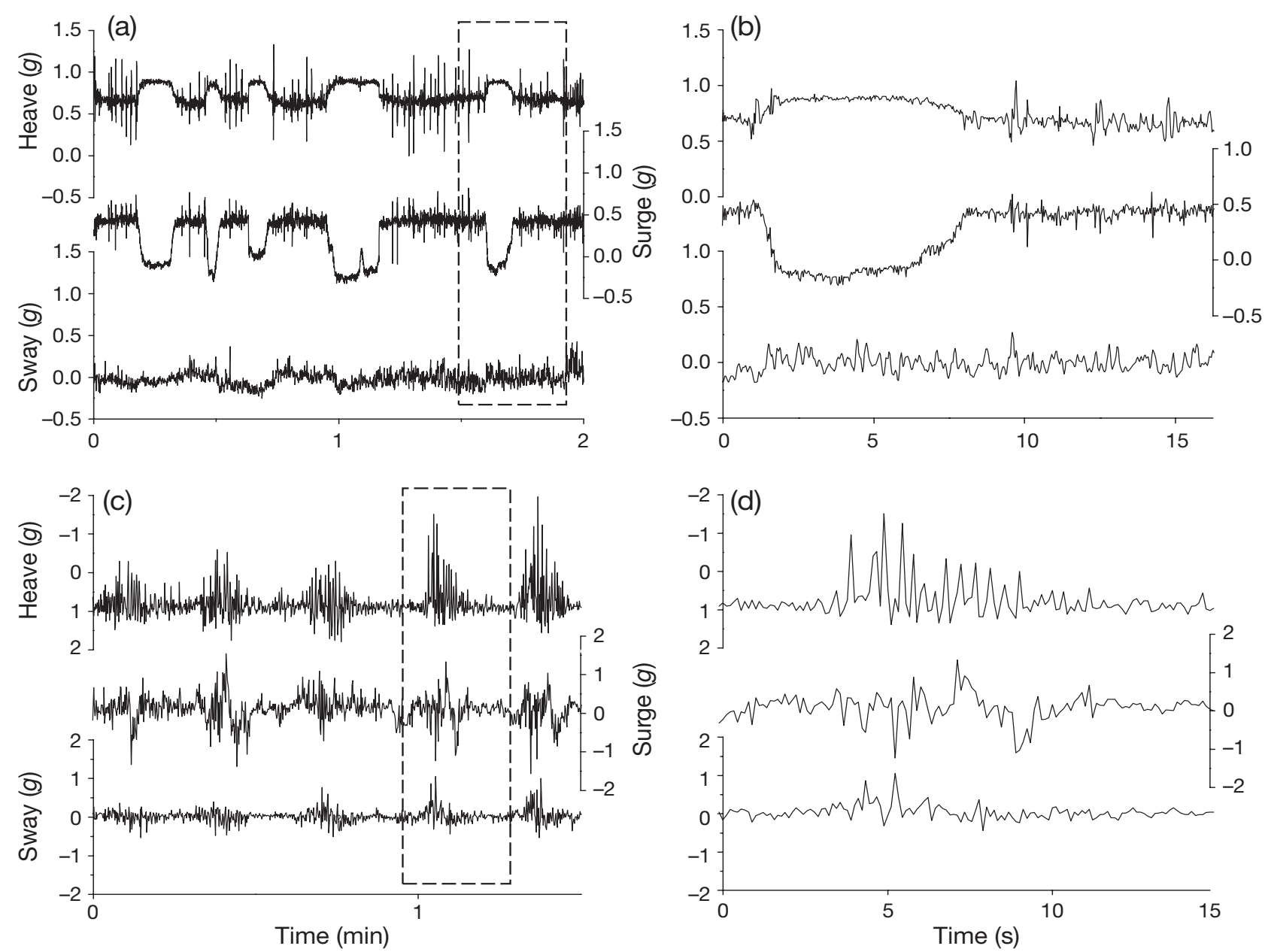

Fig. 8. Lama guanicoe and Phalacrocorax atriceps. Total acceleration (in $g$ ) for (a) a guanaco over periods when the head was down (surge $\leq 0$ ) and there was little dynamic acceleration when the animal was grazing, interspersed with walking (mean surge $=0.5$, rhythmic increases in dynamic acceleration), as shown in greater detail in (b). (c) A cormorant washing at the water surface; its horizontal posture is evident in the mean values of heave $(1 \mathrm{~g})$ and surge $(0 \mathrm{~g})$, and the sudden increases in heave are indicative of wing-beats; shown in greater detail in (d)
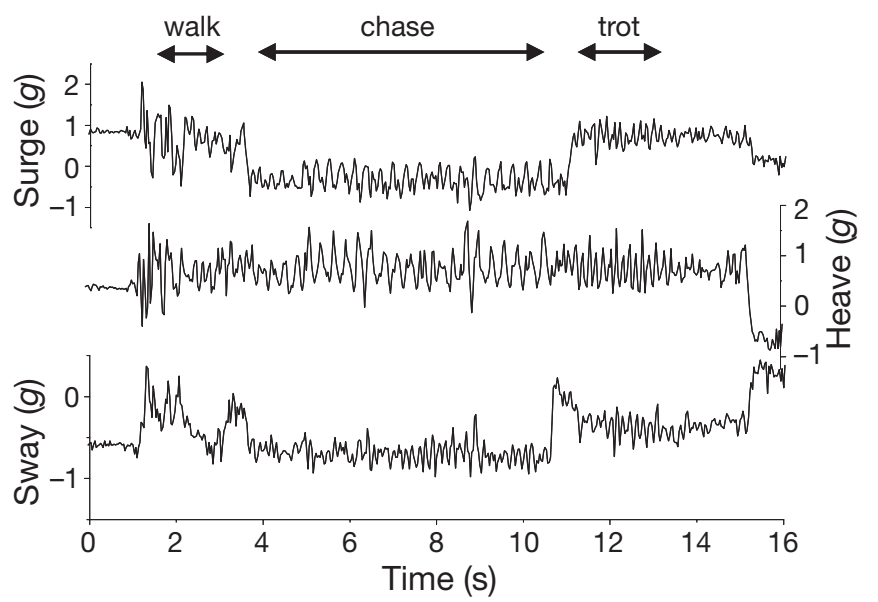

Fig. 9. Acinonyx jubatus. Total acceleration in 3 axes for a cheetah before, during and after chasing bait that was dragged by a moving vehicle calibration with energy expenditure for the study species in question, as well as measurements of the necessary environmental parameters (Wilson et al. 2006). Such information can be used in specific conservation problems both at an individual level, for instance, in monitoring behaviour of captive-bred individuals following release (Sutherland 1998), or scaled-up to estimate area-use at the population level through multiple device deployments, to assess behavioural responses to changes in the environment, land-use practice (including restoration, Caro 2007), and levels of exploitation.

Acknowledgements. E.L.C.S. is funded by a NERC studentship (award number NER/S/A/2005/13416A). Device development and deployments in Buenos Aires Zoo were supported by a Rolex Award for Enterprise, awarded to R.P.W. All the requisite local permits were acquired to work with 
wild and captive individuals. We are indebted to Dr. Miguel Rivolta, the veterinary staff and animal keepers at Buenos Aires Zoo for all their help with the captive deployments. We also thank the Organismo Provincial de Turismo for the permits to work in Punta León, and the Centro Patagónico (Conicet) for institutional support. Badger data were supplied by the Wildlife Conservation Research Unit, with thanks also to Christina Buesching, the Peoples Trust for Endangered Species and the Earthwatch Institute for their generous support. We are also grateful to Dr. Samuel Gruber and Bimini Biological Field Station for logistical support with work on lemon sharks, Steve Garner and WIMARCS for help with deployments on leatherback turtles, and Prof. Molly Lutcavage for the use of the leatherback turtle data. Deployments on cheetahs would not have been possible without the help of Dr. Mark Jago, Dave Houghton and Carla Conradie at Africat, and Dr. Emma Lee, Schalk van der Merwe and Marlice Jansen van Vuuren at the Harnas Wildlife Foundation. We are grateful for the comments of 3 anonymous referees, which greatly improved the manuscript.

\section{LITERATURE CITED}

Alexander RM (1983) Animal mechanics. Blackwell Scientific Publications, Oxford

Alexander RM (1984) The gaits of bipedal and quadrupedal animals. Int J Robot Res 3:49-59

Amlaner CJ, Macdonald DW (1980) (eds) A handbook on biotelemetry and radio tracking. Pergamon Press, Oxford

Barrey E, Desbrosse F (1996) Lameness detection using an accelerometric device. Pferdeheilkd 12:617-622

Bolger DT, Newmark WD, Morrison TA, Doak DF (2008) The need for integrative approaches to understand and conserve migratory ungulates. Ecol Lett 11:63-77

Buesching CD, Macdonald DW (2004) Variations in objectmarking activity and over-marking behaviour of European badgers (Meles meles) in the vicinity of their setts. Acta Ther 49:239-246

Caro T (2007) Behavior and conservation: a bridge too far? Trends Ecol Evol 22:394-400

Carter SP, Delahay RJ, Smith GC, Macdonald DW and others (2007) Culling-induced social perturbation in Eurasian badgers Meles meles and the management of TB in cattle: an analysis of a critical problem in applied ecology. Proc R Soc Lond B Biol Sci 274:2769-2777

Cavagna GA, Saibene F, Margaria R (1963) External work in walking. J Appl Physiol 18:1-9

Clutton-Brock TH, O'Riain MJ, Borotherton PNM, Gaynor D, Kansky R, Griffin AS, Manser M (1999) Selfish sentinels in cooperative mammals. Science 284:1640-1644

Cooke SJ, Hinch SG, Wikelski M, Andrews RD, Kuchel LJ, Wolcott TG, Butler PJ (2004) Biotelemetry: a mechanistic approach to ecology. Trends Ecol Evol 19:334-348

Culik B, Wilson RP, Bannasch R (1994) Underwater swimming at low energetic cost by pygoscelid penguins. J Exp Biol 197:65-78

Currey JD (1984) The mechanical adaptations of bones. Princeton University Press, Princeton

Fossette S, Corbel H, Gaspar P, Le Maho Y, Georges JY (2008) An alternative technique for the long-term satellite tracking of leatherback turtles. Endang Species Res 4:33-41

Gómez Laich A, Wilson RP, Quintana F, Shephard ELC (2008) Identification of imperial cormorant Phalacrocorax atriceps behaviour using accelerometers. Endang Species Res 10:29-37

> Gremillet D, Pichegru L, Siorat F, Georges JY (2006) Conservation implications of the apparent mismatch between popu- lation dynamics and foraging effort in French northern gannets from the English Channel. Mar Ecol Prog Ser 319:15-25

Halsey LG, Shepard ELC, Hulson CJ, Venables MC, White $\mathrm{CR}$, Jeukendrup AE, Wilson RP (in press) Acceleration versus heart rate for estimating energy expenditure and speed during locomotion in animals: tests with an easy model species, Homo sapiens. Zoology

Hart BL (1988) Biological basis of the behavior of sick animals. Neurosci Biobehav Rev 12:123-137

Herren R, Sparti A, Aminian K, Schutz Y (1999) The prediction of speed and incline in outdoor running in humans using accelerometry. Med Sci Sports Exerc 31:1053-1059

Jedrzejewski W, Schmidt K, Theuerkauf J, Jedrzejewska B, Okarma H (2001) Daily movements and territory use by radio-collared wolves (Canis lupus) in Bialowieza Primeval Forest in Poland. Can J Zool 79:1993-2004

Kato A, Ropert-Coudert Y, Gremillet D, Cannell B (2006) Locomotion and foraging strategy in foot-propelled and wing-propelled shallow-diving seabirds. Mar Ecol Prog Ser 308:293-301

> Kawabe R, Nashimoto K, Hiraishi T, Naito Y, Sato K (2003a) A new device for monitoring the activity of freely swimming flatfish, Japanese flounder Paralichthys olivaceus. Fish Sci 69:3-10

Kawabe R, Kawano T, Nakano N, Yamashita N, Hiraishi T, Naito Y (2003b) Simultaneous measurement of swimming speed and tail beat activity of free-swimming rainbow trout Oncorhynchus mykiss using an acceleration datalogger. Fish Sci 69:959-965

Macdonald DW, Newman C (2002) Badger (Meles meles) population dynamics in Oxfordshire, UK. Numbers, density and cohort life histories, and possible role of climate change in population growth. J Zool (Lond) 256:121-138

Marker LL, Muntifering JR, Dickman AJ, Mills MGL, Macdonald DW (2003) Quantifying prey preferences of freeranging Namibian cheetahs. S Afr J Wildl Res 33:43-53

Martin P, Bateson G (2007) Measuring behaviour: an introductory guide. Cambridge University Press, Cambridge

> McClelland BE (1991) Courtship and agonistic behavior in mouflon sheep. Appl Anim Behav Sci 29:67-85

Nelson B (1980) Seabirds. Their biology and ecology. Hamlyn, London

Ogilvy CS, Dubois AB (1981) The hydrodynamic drag of swimming bluefish (Pomatomus saltatrix) in different intensities of turbulence variation with changes of buoyancy. J Exp Biol 92:67-85

Pennycuik CJ (1972) Animal flight, Vol 33. Hodder, London

Ponganis PJ, Ponganis EP, Ponganis KV, Kooyman GL, Gentry RL, Trillmich F (1990) Swimming velocities in otariids. Can J Zool 68:2105-2112

Randall DA, Marino J, Haydon DT, Sillero-Zuburi C and others (2006) An integrated disease management strategy for the control of rabies in Ethiopian wolves. Biol Conserv 131:151-162

Ropert-Coudert Y, Grémillet D, Ryan PG, Kato A, Naito Y, Le Maho Y (2004) Between air and water: the plunge dive of the Cape gannet Morus capensis. Ibis 146:281-290

Ropert-Coudert Y, Kato A, Wilson RP, Cannell B (2006) Foraging strategies and prey encounter rate of free-ranging little penguins. Mar Biol 149:139-148

Sato K, Naito Y, Kato A, Niizuma Y and others (2002) Buoyancy and maximal diving depth in penguins: Do they control inhaling air volume? J Exp Biol 205:1189-1197

> Sato K, Mitani Y, Cameron MF, Siniff DB, Naito Y (2003) Factors affecting stroking patterns and body angle in diving Weddell seals under natural conditions. J Exp Biol 206: 1461-1470 
Sato K, Watanuki Y, Takahashi A, Miller PJO and others (2007) Stroke frequency, but not swimming speed, is related to body size in free-ranging seabirds, pinnipeds and cetaceans. Proc R Soc Lond B Biol Sci 274:471-477

Schmidt-Nielsen K (1997) Animal physiology: adaptation and environment. Cambridge University Press, Cambridge

Schreer JF, Testa JW (1995) Statistical classification of diving behaviour. Mar Mamm Sci 11:85-93

Shepard ELC, Wilson RP, Liebsch N, Quintana F, Gómez Laich A, Lucke K (2008) Flexible paddle sheds new light on speed: a novel method for the remote measurement of swim speed in aquatic animals. Endang Spec Res 4:157-164

Sutherland WJ (1998) The importance of behavioural studies in conservation biology. Anim Behav 56:801-809

Svagelj W, Quintana F (2007) Sexual size dimorphism and sex determination by morphometric measurements in breeding imperial shags (Phalacrocorax atriceps). Waterbirds 30:97-102

Tanaka H, Tagaki Y, Naito Y (2001) Swimming speeds and buoyancy compensation of migrating adult chum salmon Oncorhynchus keta revealed by speed/depth/acceleration data logger. J Exp Biol 204:3895-3904

- Taylor CR, Heglund NC, Maloiy GMO (1982) Energetics and mechanics of terrestrial locomotion. 1. Metabolic energyconsumption as a function of speed and body size in birds and mammals. J Exp Biol 97:1-21

Tsuda Y, Kawabe R, Tanaka H, Mitsunaga Y, Hiraishi T, Yamamoto K, Nashimoto K (2006) Monitoring the spawning behaviour of chum salmon with an acceleration data logger. Ecol Freshw Fish 15:264-274

Walker BG, Boersma PD (2003) Diving behavior of Magellanic penguins (Spheniscus magellanicus) at Punta Tombo, Argentina. Can J Zool 81:1471-1483

- Watanabe Y, Izawa M, Kato A, Ropert-Coudert Y, Naito Y (2005) A new technique for monitoring the detailed behaviour of terrestrial animals: a case study with the domestic cat. Appl Anim Behav Sci 94:117-131

- Watanuki Y, Niizuma Y, Gabrielsen GW, Sato K, Naito Y (2003) Stroke and glide of wing-propelled divers: deep

Editorial responsibility: Brendan Godley,

University of Exeter, Cornwall Campus, UK diving seabirds adjust surge frequency to buoyancy change with depth. Proc R Soc Lond B Biol Sci 270: $483-488$

> Watanuki Y, Takahashi A, Daunt F, Wanless S, Harris M, Sato K, Naito Y (2005) Regulation of stroke and glide in a footpropelled avian diver. J Exp Biol 208:2207-2216

> Watanuki Y, Wanless S, Harris M, Lovvorn JR, Miyazaki M, Tanaka H, Sato K (2006) Swim speeds and stroke patterns in wing-propelled divers: a comparison among alcids and a penguin. J Exp Biol 209:1217-1230

Wilson RP, Culik BM, Peters G, Bannasch R (1996) Diving behaviour of gentoo penguins, Pygoscelis papua; factors keeping dive profiles in shape. Mar Biol 126:153-162

Wilson RP, Putz K, Peters G, Culik B, Scolaro JA, Charrassin JB, Ropert-Coudert Y (1997) Long-term attachment of transmitting and recording devices to penguins and other seabirds. Wildl Soc Bull 25:101-106

> Wilson RP, Ropert-Coudert Y, Kato A (2002) Rush and grab strategies in foraging marine endotherms: the case for haste in penguins. Anim Behav 63:85-95

Wilson RP, White CR, Quintana F, Halsey LG, Liebsch N, Martin GR, Butler PJ (2006) Moving towards acceleration for estimates of activity-specific metabolic rate in free-living animals: the case of the cormorant. J Anim Ecol 75: 1081-1090

Wilson RP, Shepard ELC, Liebsch N (2008) Prying into the intimate details of animal lives: use of a daily diary on animals. Endang Species Res 4:123-137

Yoda K, Sato K, Niizuma Y, Kurita M, Bost CA, Le Maho Y, Naito Y (1999) Precise monitoring of porpoising behaviour of Adélie penguins determined using acceleration data loggers. J Exp Biol 202:3121-3126

Yoda K, Naito Y, Sato K, Takahashi A, Nishikawa J, RopertCoudert Y, Kurita M, Le Maho Y (2001) A new technique for monitoring the behaviour of free-ranging Adélie penguins. J Exp Biol 204:685-690

Zijlstra W (2004) Assessment of spatio-temporal parameters during unconstrained walking. Eur J Appl Physiol 92: $39-44$

Submitted: October 22, 2007; Accepted: February 8, 2008 Proofs received from author(s): March 17, 2008 